\title{
The Extent of and Reasons for Non Re- Enrollment: A Case of Korea National Open University
}
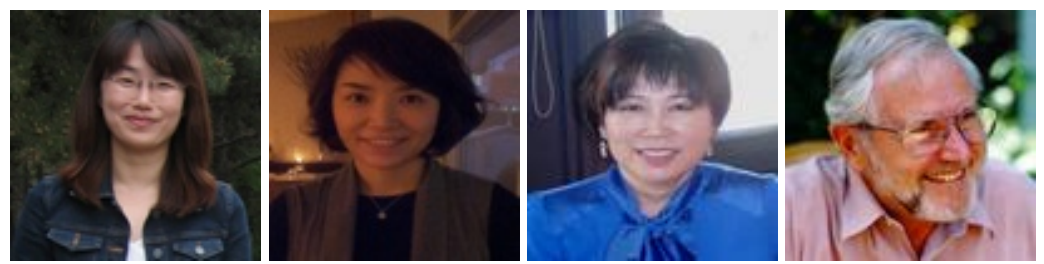

Hyoseon Choi ${ }^{1}$, Yekyung Lee ${ }^{2}$, Insung Jung ${ }^{3}$, and Colin Latchem ${ }^{4}$

${ }^{1}$ Korea National Open University, Korea, Republic of, ${ }^{2}$ Sogang University, Korea, Republic of, ${ }^{3}$ International Christian University, Japan, ${ }^{4}$ Open Learning Consultant, Australia

\section{Abstract}

Despite continuous efforts to increase retention, dropout rates are high in distance universities. The objectives of this study were: 1) to investigate the extent and causes of non re-enrollment at a mega university, Korea National Open University; and 2) to suggest actions to improve the retention of students, in general, and those with higher risks of dropout in particular. A survey designed to establish the student demographics and the students' main reasons for non re-enrollment was carried out during spring, 2009 with 1,353 respondents. The results indicate that a lack of feedback from the instructors, heavy workload, and difficulties in studying at a distance were the main reasons for non re-enrollment. The learners' perceptions of the value of the degrees and their ages, gender, and educational backgrounds were also found to be significant factors in decisions not to re-enroll. The suggested solutions for reducing non reenrollment include: a decrease in the number of required credit hours' study per semester; the provision of stronger social support; the introduction of a more flexible enrollment system; and better use of the available technology and infrastructure to help both students and instructors build stronger learning communities.

Keywords: Causes of dropout; distance learner; dropout; dropout rates; non reenrollment 


\section{Introduction}

Maintaining distance learners' enrollments and motivation is always a challenge. Even well-established distance education (DE) institutions report dropout rates of over $50 \%$ (Simpson, 2003). For example, the University of Phoenix lost $62 \%$ of its first-time fulltime bachelor degree students who had enrolled in the fall of 2009 (University of Phoenix, 2012). In Asian DE institutions, student dropout or non re-enrollment rates range from 50\% to 80\% (Fozdar, Kumar, \& Kannan, 2006). At Korea National Open University (KNOU), the dropout rate has been as high as 58\% (Hong, Kwon, \& Lee, 2004). High dropout or non re-enrollment rates in DE universities give rise to a number of major concerns:

1. It reveals that these universities, which are expressly set up to achieve greater access and equity, are failing to meet the expectations of their students, communities, and their funding bodies.

2. It suggests that there are failings in the quality of the programs and/or support, which diminishes the reputation of $\mathrm{DE}$ and leads to doubts about the costs and benefits of this mode.

3. Such attrition means that the cost per graduate, as opposed to the cost per enrollee, is high, thus destroying the argument that DE universities achieve economies of scale. It may also mean lost revenue.

4. Dropout may lead to students having lower self-esteem, being disillusioned with the system, and losing their commitment to learning, all of which can have longterm social and economic repercussions.

Regarding all of these, it is important to acknowledge the extent of, and identify the causes for, dropout in the Asian context, where 10 mega universities and around 100 dedicated DE institutions serve the largest number of distance learners in the world. Understanding these causes can inform remedial actions that can be taken by policymakers, faculty members, and others involved in the system to assure efficiency and effectiveness in the learning provision. To do this requires a systemic review. However, most studies into non re-enrollment and non-completion (for example, Allen, 1994; Fozdar et al., 2006) have been conducted at the course level, making it difficult to understand the overall extent and reasons for dropout. In this case, the study concerns the extent of, or reasons for, dropout at the institutional level. Specifically, the focus was on the 146,374 Korea National Open University (KNOU) students who, for whatever reason, failed to re-enroll in their studies in the spring of 2009.

The term dropout is used to describe those students who do not re-enroll for a program, do not submit assignments, fail to take exams, or withdraw from their studies (Simpson, 2002). The term stop-outs refers to students who drop out of programs temporarily with the intention of returning later to their studies. In this study, the term non re enrollment is specifically used to refer to students who had enrolled in a program for at least one semester but then decided not to re-enroll at all. 
Specifically, this study was undertaken to find answers to the following questions:

- What is the extent of non re-enrollment among KNOU students?

- What are the predominant reasons for their non re-enrollment?

\section{Literature Review}

\section{Factors Explaining DE Persistence}

Numerous studies have been undertaken in regard to student persistence. Tinto (1975) proposed that student persistence is a consequence of academic and social integration within the institution, and that it is student interaction with peers and faculty that results in commitment to institutional goals and mores. Kember (1995) drew on Tinto's model to explain student retention in terms of a combination of pre-determined personal characteristics and the processes of academic and social integration. Bean and Metzner (1985) developed a non-traditional student attrition model, highlighting the strong impact of environmental variables on psychological outcomes that led to the intention to leave and finally drop out. They posited that such external variables as personal finances, hours of employment, degree of external encouragement and support, family responsibilities, and opportunities to transfer to other programs or institutions have a greater effect on non-traditional student attrition than the academic-social integration variables.

Recognizing that personal, institutional, and environmental factors are all influential in success or failure in DE, Rovai (2003) synthesized Tinto's and Bean and Metzner's attrition models and developed the composite persistence model (CPM). This model integrates two prior-to-admission factors (student characteristics and student skills) and two sets of after-admission-factors (external and internal factors) to explain the reasons for student persistence in online education programs. Other researchers have drawn on Rovai's model to identify factors influencing dropout at DE institutions. For example, Lee, Choi, and Kim (2012) used this to identify the differences between the characteristics in online students who persist and in those who fail to complete their studies.

Simpson (2006) suggests that institutions should take specific proactive measures to prevent dropout by identifying students at risk at an early stage and then investigating the extent to which certain personal factors and circumstances conjoin to play a part in student dropout. For instance, gender may not be a critical factor for predicting persistence overall, but it could be a significant factor if females perceived a lack of interaction as a barrier to study in large online classes in which frequent social presence and teacher presence were difficult to achieve. 
Studies show that not only are personal characteristics, such as resilience (Kemp, 2002), and family and/or workplace responsibilities (Ashby, 2004), associated with persistence, but so are socio-demographic factors such as previous education levels and achievements, gender, age, and occupation (Woodley \& Parlett, 1983). Other studies evidence the strong influence of institutional factors. For example, Fozdar et al. (2006) found that the main causes of dropout from a BSc program at the Indira Gandhi National Open University in India were program/course and support-related rather than personal: study centers being too far from where the students lived, insufficient academic support, and courses and courseware being too difficult for the learners to comprehend. In a US context, Frydenberg (2007) found dropout to be more attributable to course problems or work/ learning schedule conflict than students' personal problems in online study. At KNOU, several studies (Hong et al., 2004; Kim, 1985; Kim, Hong, Han, Sung, \& Lee, 1994; Park \& Park, 1990) have indicated heavy demands at work and unfamiliarity with DE methods and expectations as the two main causes of dropout.

\section{A Proposed Framework for Examining Non-Completion by DE Students}

To address the problem of non-completion, a framework for identifying the main factors for non-completion was developed which was based on previous dropout studies. This was an adaptation of Tinto's model (1993), one which makes a distinction between preentry and post-entry factors for persistence and dropout. For the purposes of this study, pre-admission student characteristics were categorized into internal and external factors. Internal factors include students' gender, educational background, and age. External factors include marital status, occupation, and perceptions of value of the degree. It should be noted that burdens of workload and/ or family demands, another major factor for dropout (Ashby, 2004), are heavily related to the age, gender, marital status, and employment status of the students. Data on the students' skills, such as selfdirected learning and time-management skills, were not able to be collected due to administrative limitations.

The post-entry factors or barriers of DE, identified in previous studies and considered in this investigation were: institution related variables, course related variables, socioeconomic variables, disposition variables, and circumstantial variables.

- The institution related variables pertain to institutional climate and support which influence the students' motivation and learning (Fozdar et al., 2006; Panda, Raza, Khan, Garg, \& Garba, 2004; Shin \& Kim, 1999; Tinto, 1975).

- The course related variables include such elements as appropriateness of courses (Rovai, 2003), and quality of teaching (Comfort, Baker, \& Cairns, 2002).

- The socio-economic variables refer to such factors as the students' location, socio-economic status, and work and family commitments (Kember, 1995; Morris, Wu, \& Finnegan, 2005; Tinto, 1975). 
- The disposition variables include elements such as commitment, motivation, and attitude towards study (Bean \& Metzner, 1985; Comfort et al., 2002).

- The circumstantial variables are personal/family/job responsibilities, access to technology and other learning support, and social and academic support (Bean \& Metzner, 1985; Shin \& Kim, 1999).

The overall framework for this study is shown in Figure 1. Barriers of DE are perceived differently based on pre-admissions student factors, and those perceptions lead to reenrollment decisions.
Student Characteristics
Barriers for DE
Persistence Decision

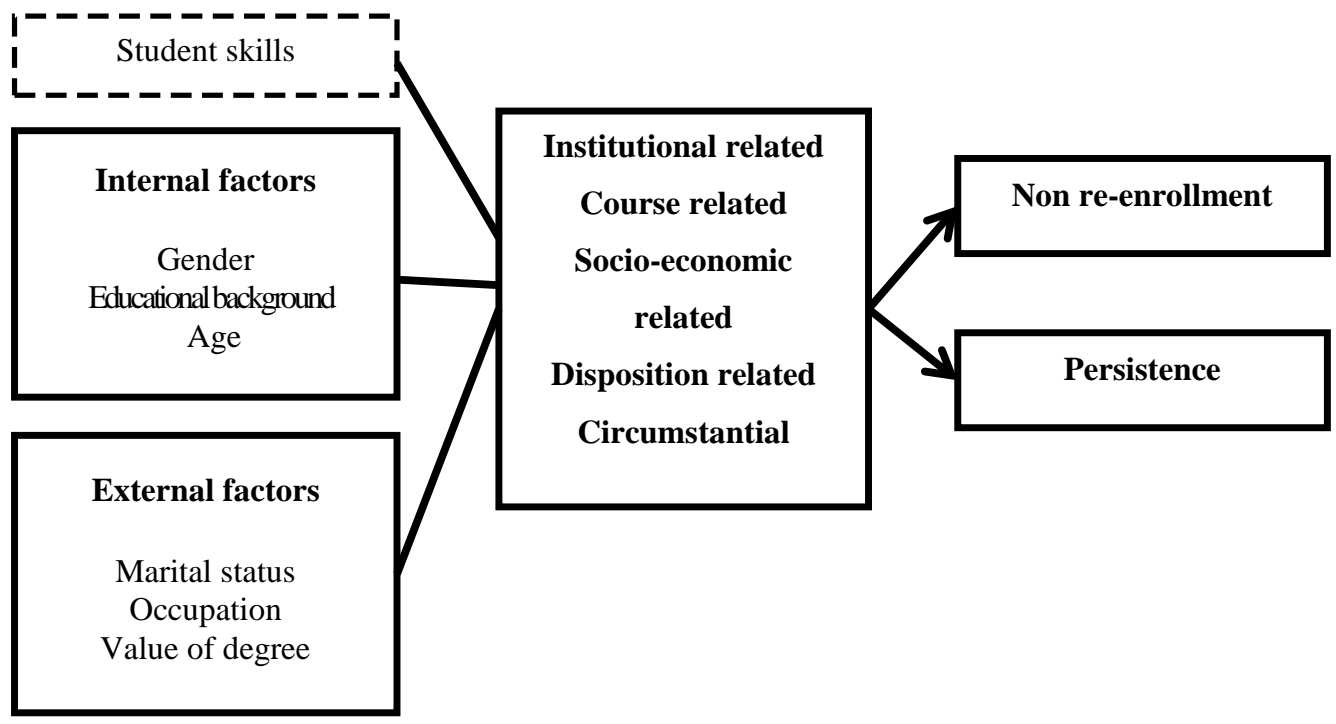

Figure 1. Framework of study into DE persistence and dropout at KNOU.

\section{The Study Context: Korea National Open University}

The Korea National Open University (KNOU) was established in 1972. It is the largest distance learning institution in South Korea and the only wholly distance teaching institution in the country. It offers lifelong education to working adults through its undergraduate, graduate, and non-degree programs.

KNOU offers undergraduate degree and non-degree programs across 21 departments in four colleges (Liberal Arts, Social Sciences, Natural Sciences, and Education), and masters level studies through 17 departments. It offers over 800 courses a year and has 148 full-time faculty, 4 visiting professors, 530 full-time administrative staff, over 3,000 part-time lecturers and tutors, and 54 media production specialists. 
The main campus is in the South Korean capital, Seoul, and there are 13 regional campuses in the major cities and 32 study centers in the smaller cities. Policy-making, planning, course design and development, and audio, TV, e-learning, and textbook production are all carried out on the main campus. Tutoring services, examinations, and learner support are provided in the regional campuses, and counseling, administration, and student activities are offered in the study centers. To support students' learning, KNOU provides face-to-face regular lecture sessions, travelling teacher systems, and personal tutor systems. Thirty percent of the over 180,000 enrolled students attend optional face-to-face classes or participate in real-time, interactive video conferencing at the regional study centers. Seventy percent of the students depend upon the $59 \%$ of courses that take the form of streamed video lectures online plus synchronized PowerPoint slides, the $29 \%$ of courses that are broadcast nationally through cable, satellite and IPTV (Internet protocol television) with the studio set up for student questions and feedback, the $11 \%$ that are offered in web-based multimedia forms, and the remainder that are audio-based. In all courses, textbooks are still the primary source of content, and there are also other supplementary or optional print or online resources. The KNOU's online system provides a space for uploading exam papers, general Q\&A, and class discussions. However, interactive components are generally lacking in these various modes of courses mainly due to a large number of enrollees and a lack of teachers and tutors.

\section{Method}

\section{Participants}

In order to identify the causes for dropout at KNOU, 146,374 students who had enrolled prior to the spring of 2009 but who then failed to re-enroll in the spring of 2009 (nonenrollees) were invited to participate in an online survey conducted between 13-17 April, 2009. After the initial survey request, three more reminders were sent to the students to try to maximize the response rates. In the event, 1,353 students responded. Table 1 details the demographics of these respondents. These data were found to be comparable with the demographics of previous KNOU dropout studies. The majority of the respondents were in their 30s or 40s. About half were female and around two-thirds were married. One-third of respondents were high school graduates and most of them were in employment. 
Table 1

Demographics of Respondents

\begin{tabular}{|c|c|c|c|}
\hline \multirow{2}{*}{\multicolumn{2}{|c|}{ Items }} & \multicolumn{2}{|c|}{ Respondents } \\
\hline & & \multirow{2}{*}{$\begin{array}{l}\begin{array}{l}\text { Frequency } \\
\text { (N) }\end{array} \\
140 \\
\end{array}$} & \multirow{2}{*}{$\begin{array}{l}\begin{array}{l}\text { Percentage } \\
\text { (\%) }\end{array} \\
10.3\end{array}$} \\
\hline \multirow{6}{*}{ Age group } & $21-30$ & & \\
\hline & $31-40$ & 646 & 47.7 \\
\hline & $41-50$ & 372 & 27.5 \\
\hline & $51-60$ & 167 & 12.3 \\
\hline & Over 60 & 28 & 2.1 \\
\hline & Total & 1,353 & 100 \\
\hline \multirow{3}{*}{ Gender } & Male & 619 & 45.8 \\
\hline & Female & 734 & 54.2 \\
\hline & Total & 1353 & 100.0 \\
\hline \multirow{4}{*}{$\begin{array}{l}\text { Marital } \\
\text { Status }\end{array}$} & Married & 915 & 67.6 \\
\hline & Single & 406 & 30.0 \\
\hline & Separated & 32 & 2.4 \\
\hline & Total & 1,353 & 100.0 \\
\hline \multirow{7}{*}{$\begin{array}{l}\text { Educational } \\
\text { background }\end{array}$} & High school graduate & 431 & 31.9 \\
\hline & Matriculation & 82 & 6.1 \\
\hline & College graduate & 392 & 29.0 \\
\hline & University Graduate & 309 & 22.8 \\
\hline & Postgraduate & 122 & 9.0 \\
\hline & Other & 17 & 1.3 \\
\hline & Total & 1,353 & 100.0 \\
\hline \multirow{6}{*}{$\begin{array}{l}\text { Employment } \\
\text { status }\end{array}$} & Full-time & 866 & 64.0 \\
\hline & Part-time & 71 & 5.2 \\
\hline & Unemployed/looking for work & 68 & 5.0 \\
\hline & Unemployed/not looking work & 94 & 6.9 \\
\hline & Other & 254 & 18.8 \\
\hline & Total & 1,353 & 100.0 \\
\hline \multirow{4}{*}{$\begin{array}{l}\text { Decision on } \\
\text { non re- } \\
\text { enrollment }\end{array}$} & I plan to resume my studies at some time in the future & 718 & 53.1 \\
\hline & I no longer plan to undertake any studies & 184 & 13.6 \\
\hline & I am not sure & 451 & 33.3 \\
\hline & Total & 1,353 & 100 \\
\hline \multirow{3}{*}{$\begin{array}{l}\text { Value of } \\
\text { degree }\end{array}$} & I felt I no longer needed the degree & 117 & 8.6 \\
\hline & I felt the degree had little value in the market & 144 & 10.6 \\
\hline & I felt I could get where I wanted without the degree & 180 & 13.3 \\
\hline
\end{tabular}

\section{Survey Instrument}

The online survey was developed to identify the reasons given by the respondents for not re-enrolling. The survey was reviewed and revised by two DE research professionals, and completed with the help of feedback from two graduate students.

The final survey comprised 14 questions regarding personal demographics, the original reasons for enrolling in the programs, students' perceptions of the value of the degrees in terms of their careers, the students' future plans and their previous experience with 
DE, plus 21 questions regarding their reasons for non-enrollment. Following the conceptual framework presented in Figure 1, the survey questions were designed to elicit answers on the institution-related, course-related, socio-economic, dispositionrelated, circumstantial, and emotional reasons for not re-enrolling. The students were asked to respond by choosing one of 'yes', 'no', or 'not sure' as their reasons.

\section{Procedure}

The URL address of the questionnaire and details of the objectives and participation methods were emailed to the target group. To gain assent, the email included a paragraph stating "If you agree to participate in this survey, insert your email address in the blank box and click the 'Continue' button."

\section{Data Analysis}

Descriptive data was analyzed to identify demographic characteristics and predominant reasons for non re-enrollment. Confirmatory factor analysis (CFA) was used to confirm the theoretical model (Figure 1) of this study. Structural equation modeling (SEM) was used in order to identify relationships among the variables of the model that contribute to non re-enrollment. In order to identify the most dominant factors within the framework, survey items to which students predominantly answered yes as their reasons for non re-enrollment were analyzed through frequency analysis. For analysis, the answers yes or no were coded as 1 and 0 . And the learners' plans to continue or stop their study were coded as 1 for resume studying and 2 for dropout.

\section{Results}

\section{Extent of Non Re-Enrollment}

Table 2 shows the numbers of registered, formally enrolled, and non re-enrolled students ratios between 2007 and 2011. Despite a slight decrease in non-enrollment rates between 2007 and 2011, there seems to be no noticeable improvement in overall enrollment. 
Table 2

Non-Enrollment Rates at KNOU between 2007 and 2011

\begin{tabular}{|l|l|l|l|l|}
\hline Year & $\begin{array}{l}\text { Registered } \\
\text { (c) }\end{array}$ & Enrollments & $\begin{array}{l}\text { Non-enrollments } \\
\text { (d) }\end{array}$ & $\begin{array}{l}\text { Non-enrollment } \\
\text { ratio } \\
\text { (d/c×100: \%) }\end{array}$ \\
\hline 2007 & 596,967 & 311,632 & 285,335 & 47.80 \\
\hline 2008 & 599,693 & 311,074 & 288,619 & 48.13 \\
\hline 2009 & 608,658 & 344,562 & 264,096 & 43.39 \\
\hline 2010 & 632,545 & 362,576 & 269,969 & 42.68 \\
\hline 2011 & 614,262 & 335,753 & 273,061 & 44.45 \\
\hline
\end{tabular}

Table 3 shows the total enrollment across all KNOU courses, the number and ratio of non-examinees, and the number and ratio of non-completion students between 2007 and 2011. These show no decrease in non-completion rates during this period, despite increased provision of learner support.

Table 3

Course Non-Completion Rate: 2007 to 2011

\begin{tabular}{|l|l|l|l|l|l|l|l|l|l|}
\hline \multirow{2}{*}{ Year } & $\begin{array}{l}\text { Total } \\
\text { enrollments } \\
\text { across } \\
\text { all courses } \\
\text { (a) }\end{array}$ & Examinees & $\begin{array}{l}\text { Non- } \\
\text { examinees } \\
\text { (b) }\end{array}$ & $\begin{array}{l}\text { Non- } \\
\text { examinees } \\
\text { ratio } \\
\text { (b/ax100: \%) }\end{array}$ & Examinees & $\begin{array}{l}\text { Fon- } \\
\text { examinees } \\
\text { (c) }\end{array}$ & $\begin{array}{l}\text { Non- } \\
\text { examinees } \\
\text { ratio } \\
\text { (c/ax100: \%) }\end{array}$ & $\begin{array}{l}\text { Non- } \\
\text { completion } \\
\text { (d) }\end{array}$ & $\begin{array}{l}\text { Ratio } \\
\text { (d/ax100: \%) }\end{array}$ \\
\hline 2007 & $1,704,881$ & $1,409,284$ & 286,037 & 16.78 & $1,325,529$ & 369,792 & 21.69 & 378,338 & 22.19 \\
\hline 2008 & $1,703,029$ & $1,402,203$ & 291,317 & 17.11 & $1,318,146$ & 375,374 & 22.04 & 382,063 & 22.43 \\
\hline 2009 & $1,640,347$ & $1,397,504$ & 242,843 & 14.80 & $1,307,894$ & 332,453 & 20.27 & 357,819 & 21.81 \\
\hline 2010 & $1,688,821$ & $1,417,823$ & 270,998 & 16.05 & $1,317,325$ & 371,496 & 22.00 & 357,453 & 21.17 \\
\hline 2011 & $1,634,359$ & $1,336,488$ & 297,871 & 18.23 & $1,273,048$ & 361,311 & 22.11 & 301,982 & 18.48 \\
\hline
\end{tabular}

\section{Reasons for Non Re-Enrollment}

Confirmatory factor analysis (CFA) was carried out as the first step of analysis. CFA results indicate five factors for explaining non re-enrollment as in Table 4. Frequency statistics for the perceived reasons of non-enrollment indicated that three items, "because of a lack of feedback on my work", "because the workload was too heavy in my workplace", and "because it is difficult to study at a distance", were identified as variables displaying significantly different ratios between responses, with the majority 
answering yes. Overall, the students perceived institution-related variables to be stronger reasons for non re-enrollment; emotion-related variables seemed to have had little impact on their decisions. Unlike the hypothesized model of barriers for distance education, the fifth factor turned out to be emotional-related variables such as "feeling isolated " and "feeling depressed", rather than environmental variables.

Table 4

Reasons for Non Re-Enrollment

\begin{tabular}{|c|c|c|c|c|}
\hline \multirow{2}{*}{ Variables } & \multirow{2}{*}{ Reasons } & \multicolumn{3}{|c|}{ Frequency (\%) } \\
\hline & & Yes & No & Not Sure \\
\hline \multirow{6}{*}{$\begin{array}{l}\text { Institution } \\
\text { related } \\
\text { variable }\end{array}$} & Because of a lack of feedback on my work & 61.7 & 34.3 & 4 \\
\hline & Because of a lack of contact with other students & 47.1 & 48.3 & 4.6 \\
\hline & Because of a lack of online help and support & 46.6 & 47.2 & 6.2 \\
\hline & Because of a lack of face-to-face teaching and advice & 45.9 & 49.2 & 5 \\
\hline & Because it is difficult to study at a distance & 56.6 & 39.5 & 4 \\
\hline & Because I lacked computer/ Internet access & 12 & 83.9 & 4 \\
\hline \multirow{5}{*}{$\begin{array}{l}\text { Course related } \\
\text { variables }\end{array}$} & $\begin{array}{l}\text { Because the course was different from what I } \\
\text { expected }\end{array}$ & 45.9 & 48.9 & 5.2 \\
\hline & Because the course was not practical enough & 28.3 & 65.7 & 6 \\
\hline & Because the course I wanted was cancelled & 10.2 & 87.6 & 2.2 \\
\hline & $\begin{array}{l}\text { Because another course/ program was better suited } \\
\text { to my needs }\end{array}$ & 32.4 & 62.8 & 4.9 \\
\hline & $\begin{array}{l}\text { Because the course information was } \\
\text { inadequate/ misleading }\end{array}$ & 25.1 & 68.1 & 6.8 \\
\hline \multirow{4}{*}{$\begin{array}{l}\text { Socio- } \\
\text { economic } \\
\text { variables }\end{array}$} & Because of family demands & 35 & 62.4 & 2.6 \\
\hline & Because the workload was too heavy at job place & 64.3 & 32.9 & 2.8 \\
\hline & Because of the costs & 16.4 & 81.1 & 2.5 \\
\hline & Because of disability/ illness & 5.6 & 92.6 & 1.8 \\
\hline \multirow{4}{*}{$\begin{array}{l}\text { Disposition } \\
\text { related } \\
\text { variables }\end{array}$} & Because the course was too difficult & 37.2 & 56.3 & 6.5 \\
\hline & Because of pressures of work & 31.9 & 63.8 & 4.3 \\
\hline & Because I lacked the necessary knowledge and skills & 48.4 & 46.8 & 4.8 \\
\hline & Because I lacked the motivation & 42.8 & 53 & 4.2 \\
\hline \multirow{2}{*}{$\begin{array}{l}\text { Emotion } \\
\text { related } \\
\text { variables }\end{array}$} & Because I felt isolated & 15.7 & 81.1 & 3.3 \\
\hline & Because I felt depressed & 8.9 & 87.1 & 3.9 \\
\hline \multicolumn{2}{|l|}{ Total } & 31.6 & 63.9 & 4.4 \\
\hline
\end{tabular}

\section{Validation of Framework for Explaining Non Re-Enrollment}

The model that had been developed to establish the relationships between the personal factors and barriers found to be powerful in explaining non re-enrollment at KNOU are shown in Figure 2. The goodness-of-fit indexes for the proposed model for explaining 
non re-enrollment were $\mathrm{CFI}=.915$, TLI $=.975$, and $\mathrm{REMSEA}=.075$, indicating good fit of the model (Byrne, 2001).

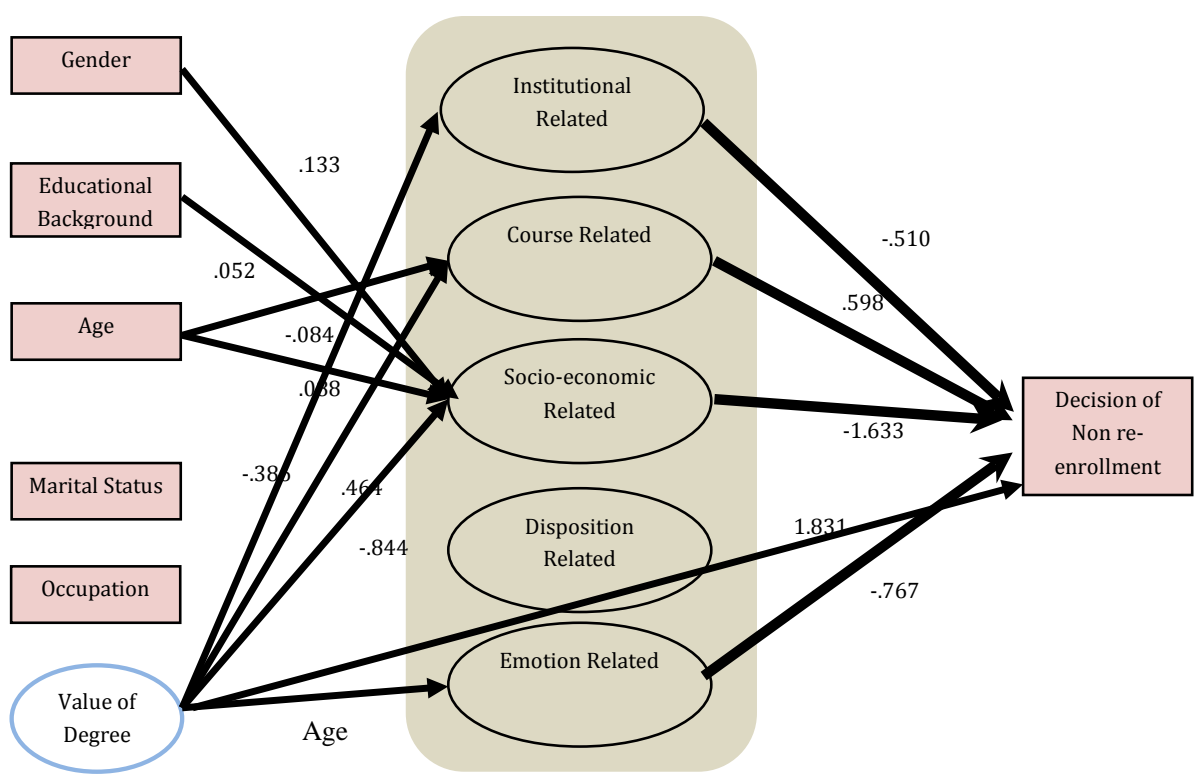

Figure 2. Non re-enrollment model.

The key finding derived from SEM was that learner's perceptions of the value of the degree had a significant influence on the institutional related, course related, socioeconomic related, and emotion related barriers. Those learners who considered the degree to be useful to their careers showed stronger tendencies to re-enroll. However, the more they value the degree, the more the course related barriers may become a stronger obstacle, while the institution, socio-economic, and emotion related barriers are less likely to be regarded as obstacles. Secondly, it was revealed that age has a statistically significant influence on non re-enrollment mediated with course related and socio-economic related barriers. The older the student, the less influence on course related and socio-economic related barriers. Finally, gender, educational background, and age affect non re-enrollment mediated by the socio-economic related variable. Females tend to re-enroll more than male by socio-economic related variable. And the higher the level of educational backgrounds, the fewer the dropouts mediated by the socio-economic related variable.

\section{Discussion}

Recognizing that learner support is the key to successful distance learning, KNOU has devised various ways of supporting its students, such as offering educational content in a variety of media formats (printed materials, MP3 files of all broadcast programs, CDROMS, and online courses), face-to-face lectures, and personalized tutoring. Despite all 
of these support systems, the current study reveals that KNOU students are still struggling with and discontinuing their studies in considerable numbers. The main reasons for this are shown to be the heavy workloads demanded in their jobs, the lack of feedback on the students' work, and a dislike of distance learning per se. Over $64 \%$ of the respondents cited heavy workload as a main reason for their decision not to reenroll, indicating that they had great difficulty in finding time for their studies. It should be explained that KNOU students are required to enroll in five to six courses every semester. Consequently, many students focus on a limited number of courses and intentionally fail the remainder in the semester (Shin \& Kim, 2009). There is clearly a need to address this issue and provide a system which allows students to enroll in whatever number of courses they feel they can handle in a particular semester.

Around $62 \%$ of the respondents reported that they felt they had received insufficient feedback on their academic work. The quality and extent of feedback is well known to be an important aspect of learning, particularly in DE settings. However, it has been calculated that with 750,000 to 950,000 enrollees annually, and the current limits to the number of faculty and part-time tutors, providing more, and more detailed, feedback on all assignments to each and every student would necessitate a two-month turnaround. Hiring sufficient staff to reduce this time would exceed KNOU's financial capabilities, so, currently, this problem would appear to be intractable. However, KNOU has met with some success in encouraging and supporting informal self-help groups among its students. Students participating in such self-study groups have been shown to be more confident and successful in their studies (Park \& Kim, 2011). This suggests that the university should consider how it might make further use of face-to-face and online social interaction among students in order to increase their motivation and persistence in their studies.

Around $57 \%$ of the respondents indicated that they disliked studying at a distance. This indicates the importance of helping new students to appreciate what is involved in DE study and to develop the necessary competencies in distance learning before they actually embark on their formal studies.

Analysis of the effect of gender, educational background, age, and students' perceptions of the value of the degree provided further insights into the reasons for non reenrollment. It would appear that while at the outset women students see DE as providing a solution to balancing family and study commitments, socio-economic barriers such as family responsibilities and the demands of employment are a greater hindrance to female students than their male counterparts. This suggests a need for KNOU staff to put more effort into supporting female students, for example, by developing specific online systems to encourage and support female networking and study groups.

Students' education level prior to entering KNOU is also shown to have an impact on how these students perceive the barriers in online learning. As seen in Table 3, a 
considerable number of students failed to submit their mid-term papers. This can be explained by the fact that about $50 \%$ of the new students are high school graduates who often lack the academic writing skills required for university work (Korea National Open University, 2007). But SEM results suggest that although these students may experience greater difficulties academically, students with higher educational levels and age are more susceptible to socio-economic barriers when deciding to re-enroll. These findings indicate the need for different approaches such as group tutoring systems for learners with different educational backgrounds and of different ages.

\section{Conclusion}

Overall, it may be concluded from these findings that the KNOU system still lacks an integrated, effective, and efficient learner support system that is capable of identifying the learners' prior learning and learning capacities, responding to these factors, and ensuring pathways to successful learning and a reduction in non re-enrollment. Based on these findings, the researchers propose that KNOU should:

Develop an institution-wide system that will encourage and support increasingly independent study while maintaining social support and promoting interactions and exchanges of ideas with professors, tutors, and peers. This can be achieved by organizing:

- Pre-enrollment courses - preferably combining online and face-to-face modes to help new students develop the knowledge, skills, and attitudes needed to study successfully at distance.

- Remedial courses for students lacking the necessary study skills and courserelated prior knowledge and writing skills.

- Personalized tutoring services for all new students. These services would need to take every advantage of online technologies including mobiles and tablets. Tutoring services should also be offered to specific student groups such as female students with less formal schooling and others at risk in response to their clearly identified needs.

Construct learning environments that support peer-based learning and create a sense of belonging by actively promoting real and virtual voluntary study groups. This could be achieved by:

- Encouraging and supporting out-of-class and/or online informal learning groups wherein students share their concerns and experiences and learn from and empower each other.

- Encouraging the use of social media tools (blogs, wikis, etc.) by both instructors and students. However, alternative methods such as offline meetings should 
also be provided for those students who are unfamiliar or uncomfortable with the social media or do not have access to the tools.

- Providing online/mobile tools, such as mobile applications, to support peerbased learning and encouragement.

- Using constant RSS feeds to send new information and updates to keep students current with course activities.

Review the existing DE system and its impacts on learning processes, learning achievement, learner satisfaction, enrollment and course completion, cost-effectiveness, and efficiency. For example:

- Reduce the number of courses students must take each semester. This would both reduce the burden on the students, and make it more feasible for faculty members to offer more personalized tutoring services and more frequent feedback.

- Change the student evaluation system from that of a "one-shot examination" which mostly involves information recall to a series of formative exams, tests, or assignments which have clearer guidelines and built-in support and will help to initiate the learners into the new forms and requirements of study without placing further undue burdens on faculty and tutors.

- Make the enrollment system more flexible so that the students can enroll in courses according to their preferred learning pace.

This study was undertaken to contribute to the existing literature on student retention at $\mathrm{DE}$ institutions by presenting an overall picture of the extent and major reasons for non re-enrollment at KNOU, and to suggest solutions targeted at specific student groups. While this model was designed and applied at only one institution, by focusing on the relationship between learners' personal factors and perceived barriers for DE, this study may go some way towards suggesting how to create practical support systems that fit the different needs of various student groups in any distance education provider. However, the small number of student variables investigated and the lack of further analysis and comparison of effect sizes make it difficult to propose a coherent strategic plan for increasing retention that is guaranteed to succeed at KNOU or elsewhere. Future research therefore is needed to identify reliably effective systems and methods for retaining students. This might be done by 1) exploring retention at an institution level at various online universities in order to gain a holistic picture of student attrition; 2) examining conflicts, issues, and the consequences of implementing strategies targeting different needs of students; and 3) proposing general guidelines for motivating students to continue their studies. 


\section{Acknowledgements}

We would like to express our appreciation to Dr. Ashok Gaba at Indira Gandhi National Open University for providing an initial version of the survey for this study and to KNOU for allowing us to use its non-enrollment data. 


\section{References}

Allen, B. (1994). The student in higher education: Nontraditional student retention. CATALYST, 23(3), 19-22.

Ashby, A. (2004). Monitoring student retention in the Open University: Definition, measurement, interpretation and action. Open Learning, 19(1), 65-78.

Bean, J . P., \& Metzner, B. S. (1985). A conceptual model of nontraditional undergraduate student attrition. Review of Educational Research, 55(4), 485540 .

Byrne, B. M. (2001). Structural equation modeling with Amos: Basic concepts, applications, and programming. Mahwah, NJ : Lawrence Erlbaum.

Comfort, H., Baker, P., \& Cairns, L. (2002). A qualitative study investigating factors which help and hinder learner progression FE to HE: Report on the "Transitions Project". Leicester: Leicester College.

Fozdar, B., Kumar, L., \& Kannan, S. (2006). Study of the factors responsible for the dropouts from the BSc programme of Indira Gandhi National Open University. The International Review of Research in Open and Distance Learning, 7(3). Retrieved from http:// www.irrodl.org/ index.php/irrodl/article/view/ 291/ 747

Frydenberg, J . (2007). Persistence in university continuing education online classes. The International Review of Research in Open and Distance Learning, 8(3). Retrieved from http:// www.irrodl.org/ index.php/irrodl/article/view/375/934

Hong, S. J ., Kwon, J . H., \& Lee, M. W. (2004). Learning supporting program and its managing methods for the prevention of learning discontinuance in the first semester. Seoul: Korea National Open University.

Kember, D. (1995). Open learning courses for adults: A model of student progress. Englewood Cliffs, NJ : Educational Technology.

Kemp, W. (2002). Persistence of adult learners in distance education. The American J ournal of Distance Education, 16(2), 65-81.

Kim, H. S., Hong, Y. N., Han, K. Y., Sung, K. S., \& Lee, J . S. (1994). Studies on causes of non-enrollment in KNOU. Seoul: Korea National Open University.

Kim, P. Y. (1985). Factors on learning motivation and persistence: Preventions of dropout and improvement of learning outcomes. Seoul: Korea National Open University.

Korea National Open University (2007). 2007 enrollment statistics. Seoul: Author. 
Lee, Y., Choi, J., \& Kim, T. (2012). Discriminating factors between completers of and dropouts from online learning courses. British J ournal of Educational Technology, 4(2), 329-337.

Morris, L., Wu, S., \& Finnegan, C. (2005). Predicting retention in online general education courses. The American J ournal of Distance Education, 19(1), 23-36.

Panda, S., Raza, R., Khan, A. R., Garg, S., \&Gaba, A. (2004). Study on programme completion, and learner persistence and dropout in distance education. Indira Gandhi National Open University and International Research Foundation for Open Learning, UK.

Park, J ., \& Kim, M. (2011). The current state and effects of out-of-class learning activities at KNOU. Seoul: Korea National Open University.

Park, D. J ., \& Park, J . W. (1990). Employed students' life and learning problems. Seoul: Korea National Open University.

Rovai, A. P. (2003). In search of higher persistence rates in distance education online programs. Internet and Higher Education, 6(1), 1-16.

Shin, C. H., \& Kim, J . (2009). Needs survey for improving quality of teaching and learning. Seoul: Korea National Open University.

Shin, N., \& Kim, J . (1999). An exploration of learner progress and dropout in Korea National Open University. Distance Education-An International J ournal, 20(1), 81-95.

Simpson, O. (2002). Supporting students in online, open and distance learning. London: Routledge.

Simpson, O. (2003). Student retention in online, open and distance learning. London: Routledge.

Simpson, O. (2006). Predicting student success in open and distance learning. Open Learning, 21(2), 125-138.

Tinto, V. (1975). Dropouts from higher education: A theoretical synthesis of the recent literature. A Review of Educational Research, 45, 89-125.

Tinto, V. (1993). Leaving college: Rethinking the causes and cures of student attrition ( $2^{\text {nd }}$ ed.). Chicago: University of Chicago Press.

University of Phoenix (2012). Consumer information guide 2011-2012. Retrieved from http://cdn.assets-phoenix.net

Woodley, A., \& Parlett, M. (1983). Student dropout. Teaching at a Distance, 24(1), 2-23. 


\section{Athabasca University $\mathbf{A}$}

(c) 